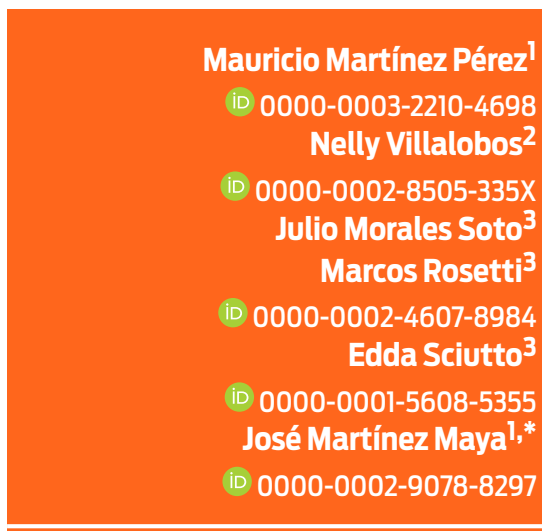

${ }^{1}$ Departamento de Medicina Preventiva, Facultad de Medicina Veterinaria y Zootecnia, Universidad Nacional Autónoma de México, Ciudad de México, México

${ }^{2}$ Departamento de Patología, Facultad de Medicina Veterinaria y Zootecnia, Universidad Nacional Autónoma de México, Ciudad de México, México

${ }^{3}$ Departamento de Inmunología, Instituto de Investigaciones Biomédicas. Universidad Nacional Autónoma de México.

*Corresponding authors: Email address: jjmm@unam.mx

\section{Movement and feeding habits of semi-confined domestic pig groups in a rural location endemic to cysticercosis}

\begin{abstract}
Free-range pigs are in the highest risk to acquire cysticercosis in endemic rural locations, although the behavioral and physiological responses to the infection are known to vary widely between pigs. Those animals reared in semi-confinement showed a group behavior that allows us to follow the herd to assess the risks of contact with the parasite. This study is aimed to determine the movement and feeding habits of pig groups raised under semi-confinement conditions, using minimally invasive procedures, applying trajectory analysis to different herds in rural settings. Pig population and subpopulations were characterized, and their movement was evaluated in two seasons of the year, using a global positioning system (GPS). Our results indicate that pig groups are formed based on human ownership and the establishment of family bonds with each other. Each group interacts with other groups in specific sites of the village. Significant differences were found in the time and distance covered by pigs in the dry and rainy seasons $(P<0.05)$, and the distance travelled by different groups were found to take place in repetitive, well-defined spaces that include moving through sewage, landfills, and open defecation sites. Due to this stability, the trajectories covered by pigs could be useful as indicators of risk factors linked to the exposure of pigs to Taenia solium.
\end{abstract}

Keywords: Epidemiology; Trajectories; Global positioning system (GPS).
Accepted: 2021-06-16 Published: 2021-07-02

@ Copyright 2021 Mauricio Martínez Pérez et al. open access $\boldsymbol{\partial}$

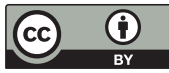

Distributed under Creative Commons CC-BY 4.0

\section{Cite this as:}

Martínez Pérez, M., Villalobos, N., Morales Soto, J., Rosetti, M., Sciutto, E., Martínez Maya, J., (2021). Movement and feeding habits of semi-confined domestic pig groups in a rural location endemic to cysticercosis Roaming habits of semi-confined pigs in rural Mexico. Veterinaria México OA, 8. Doi: 10.22201/fmvz.24486760e.2021.714 


\section{Introduction}

Pork is the second most produced and consumed meat in Mexico, with technical-intensive production having the highest market share (FIRA, 2017). Pork consumption and production have increased in recent years after the introduction of newer genetic improvement methods, the design of modern facilities, and the application of sanitary programs to improve the health of pig livestock (Guy et al., 2012; Vitali et al., 2018). As a result of these efforts, domestic production covers $80 \%$ of the demand for pork meat in Mexico (FIRA, 2017). However, pig rustic farming, very different from technical production, persists in the country. Thousands of small producers living under medium- or high-marginalization conditions rear pigs and produce pork meat with a minimal investment. While these activities do not result in a financially viable production, the food that they produce contributes to the diet of thousands of Mexican families (Martínez-Castañeda et al., 2003; Linares-Ibáñez et al., 2011).

The population structure in pig farms is defined by the productive system, with groups of animals formed by sex and age with a zootechnical perspective; thus, pigs cannot express their gregarious behavior that they would exhibit when they are roaming freely (Marotta et al., 1999).

In contrast, rustically reared pigs are housed in a pigsty, usually a roofed, dirtfloor structure; other less well-delimited areas, with or without walls, are sometimes used as pigsties. Pig feed may consist of grains and food waste, but rustically reared pigs obtain most of their diet by foraging through the village or its surroundings (Linares-Ibáñez et al., 2011; Thomas et al., 2013; Palma et al., 2017).

Although it would be desirable to enhance the economic impact of this production method, pigs fulfil important sanitary functions in rural locations by disposing of organic waste, feces of other animals, and even human feces from households lacking suitable toilets (Linares-lbáñez et al., 2011 ; Martínez et al., 1997; Copado et al., 2004). While the latter is inappropriate, it is a reality in many rural locations where sanitary services are poor or nonexistent (Aluja and Villalobos, 2000). This is relevant because of the risk for the pigs of meeting with pathogens like Taenia solium. The adult stage of this parasite lives in the small intestine of a human host, who every day excretes in the feces and into the environment one or two proglottids with thousands of eggs. When consumed by a pig, these eggs develop into a metacestode or cysticercus. The cycle is completed when humans ingest undercooked, metacestode-infected meat (Aluja and Villalobos, 2000).

To evaluate the behavior of pigs reared in semi-confinement and its link with cysticercosis, Copado et al., (2004) conducted a study on pig habits and activities. The authors found that pigs form groups including individuals of various ages and both sexes and establish a hierarchy. Usually, an adult female plays the role of herd leader and has the highest priority when feeding. Pigs prefer to feed at the cooler hours of the day (morning and afternoon), while resting at the warmer hours (noon). In the study, the authors estimated that pigs travel up to $1 \mathrm{~km}$ daily in the dry season and up to $3 \mathrm{~km}$ in the rainy season. Regarding their trajectories, the authors only mentioned that pigs usually walk in straight lines, changing direction due to terrain conditions (the presence of ravines, houses or walls) or to visit a preferred site (Copado et al., 2004).

A detailed description of pig movements results in a trajectory, which can be defined as the spatial record of the displacement of a body in time (Turchin, 1998). 
Studying trajectories could be of interest to detect population habits and sites where disease transmission would be more likely, particularly when diseases show a clear spatial-temporal pattern (Thomas et al., 2013).

This work is aimed to study and describe trajectories of pigs reared in semi-confinement in a rural location in Guerrero, Mexico, to evaluate their impact on a potential contact with the parasite. The results of this study support the interest of trajectory analysis to predict contact with pathogens and a possible infection.

\section{Material and methods}

\section{Study site}

The village of San Martín Pachivia is located at the municipality of Ixcateopan, Guerrero, at a latitude of $18^{\circ} 47^{\prime} 09^{\prime \prime} \mathrm{N}$ and a longitude of $99^{\circ} 47^{\prime} 09^{\prime \prime} \mathrm{W}$, at 1382 mamsl, with rains from June through October, a dry season from December through May, and about 1100 inhabitants. Temperature varies throughout the year, with highs and lows of $32{ }^{\circ} \mathrm{C}$ and $13{ }^{\circ} \mathrm{C}$ in April, and $27^{\circ} \mathrm{C}$ and $7{ }^{\circ} \mathrm{C}$ in December (Weather, 2021).

\section{Location of pigs}

A questionnaire was applied to household heads to build a census of the local pig population in the dry (April) and rainy seasons (September); the number of pigs per household was determined along with age, sex, and weight of each animal. The sites where pigs are reared were georeferenced through the global positioning system (GPS).

In the location, pigs are usually kept in confinement from 6:00 p.m. to 6:00 a.m. on the next day, either in pens or behind the fence of the property, which is typically built of overlapping stones or wood, approximately 1 meter tall. During the day they roam freely, and on their departure and arrival at the house they received corn grains and food waste (escamocha). Only purebred pigs remain locked up within the owners' premises.

\section{Anti-cysticercal antibodies}

When pig owners allowed it, $10 \mathrm{ml}$ of blood was obtained from each animal (141 pigs in the dry season and 116 pigs in the rainy season) to diagnose porcine cysticercosis using an ELISA protocol with T. solium cyst fluid as an antigen source, following a previously described procedure (Morales et al., 2018), with minor modifications. The test showed a sensitivity of $77.3 \%$ and a specificity of $88.6 \%$. A cross reaction with Echinococcus granulosus has been detected, this parasite has not been diagnosed in local pigs (Morales et al., 2018).

\section{Study of trajectories}

Three pig groups, composed by 9, 12, and 14 animals and whose owners accepted to participate, were included in this study. Each group was followed for two days ( 9 h each day) before the study started, to allow the animals to familiarize with the 
observer. Then, the trajectories of each group were recorded by the person who accompanied them using a Garmin ${ }^{\circledR}$ brand GPS 60 , with a margin of error of $\pm 3 \mathrm{~m}$, for three days, with continuous readings for 9 hours each day per group. General descriptors like distance and time travelled each day were quantified (Turchin, 1998). These indicators were used to describe the trajectories covered by each group and to compare the performance of the same groups during the rainy and dry seasons. Three behavior types were recorded: displacement, feeding, and resting.

\section{Statistical analysis}

Descriptive statistical parameters were calculated with the information gathered, and data in the dry season were compared with those in the rainy season. Data normality was determined with the Kolmogorov-Smirnov test (Wayne, 2002) and either a parametric or non-parametric model was used to compare groups, as appropriate. Pig trajectories were determined by using maps built from GPS records, and hypothetic movement radiuses were estimated by creating diameter buffers with respect to recorded data for the groups under study, using the software Qgis v.3.2. and Google Earth.

\section{Results}

\section{Pig population}

There were 1100 inhabitants in 253 households in the village. In total, 216 animals were counted in the census, in 33 households (13.04\%) with an average of 6.5 pigs per household. A human-pig ratio of 5.09:1 was determined. In general, pig age and weight positively correlated until the animals were 12 months-old $(P<0.01)$. Body weight values for pigs in the locations were much lower than those expected in a large scale farm, due to the breeding and feeding conditions. In the locations under study, an average monthly weight gain of $2.77 \mathrm{~kg}$ was estimated. The animals were not vaccinated nor dewormed. All pigs that lived in a farm were considered as a group. Three pig groups were selected for trajectory analysis among the 33 houses where pigs were bred in semi-confinement, and they were allowed to roam freely to forage.

\section{Quantifying anti-cysticercal antibodies in the rainy and dry seasons}

Variable seropositivity rates were found in the community at different times of the year. In the dry season, 32 (22.7\%) positive animals were found out of a total of 141 pigs, while a significantly higher frequency of 40 (34.5\%) positive animals were found in 116 pigs evaluated in the rainy season $(P=0.36)$. On the other hand, no difference was found in positivity rates in the three groups evaluated, neither between seasons nor between groups $(P>0.05)$. However, positivity was slightly higher in group 1. This indicates that, in their daily roaming, all three groups found areas where they could potentially get infected, including sites where human feces are found. 
Table 1. Composition of the three groups under study and activities recorded by season of the year. San Martín Pachivia, Guerrero, Mexico.

\begin{tabular}{l|c|c|}
\hline & \multicolumn{2}{|c|}{ Number and sex* } \\
\hline Group & Dry & Rainy \\
\hline 1 & $9(6 \mathrm{~F}, 3 \mathrm{M})$ & $7(5 \mathrm{~F}, 2 \mathrm{M})$ \\
\hline 2 & $12(9 \mathrm{~F}, 3 \mathrm{M})$ & $10(8 \mathrm{~F}, 2 \mathrm{M})$ \\
\hline 3 & $14(10 \mathrm{~F}, 4 \mathrm{M})$ & $15(10 \mathrm{~F}, 5 \mathrm{M})$ \\
\hline \multicolumn{3}{|c}{ Mean } \\
*F= Female; M = Male \\
** Mean by group
\end{tabular}

\begin{tabular}{|c|c|c|c|c|c|}
\hline \multicolumn{5}{|c|}{ Activity hours } \\
\hline \multicolumn{2}{|c|}{ Feeding } & \multicolumn{2}{c|}{ Resting } & \multicolumn{2}{c|}{ Displacement } \\
\hline Dry & Rainy & Dry & Rainy & Dry & Rainy \\
\hline 2,1 & 4,16 & 4,66 & 2,58 & 1,83 & 4,33 \\
\hline 2 & 3,5 & 5,41 & 3,75 & 2 & 3,91 \\
\hline 2,75 & 1,91 & 5,75 & 4 & 2,58 & 3,33 \\
\hline 2,283 & 3,19 & 5,273 & 2,44 & 2,137 & 3,86 \\
\hline
\end{tabular}

\section{Trajectory analysis}

All three groups had an animal count above the mean value for the community was 6.5. The mean age in each group was $8.6,8.3$, and 10 months, respectively, with a range of 2-24 months (Table 1 ).

With respect to the time spent in various activities throughout the day, resting time was longer in the dry season, with $5.27 \pm 0.67 \mathrm{~h}$ vs. $3.44 \pm 0.78 \mathrm{~h}$ in the rainy season $(P<0.01)$. Displacement time was longer in the rainy season, averaging $3.86 \pm 1.06 \mathrm{~h}$ vs. $2.13 \pm 0.435 \mathrm{~h}$ in the dry season $(P<0.01)$. Feeding time was longer in the rainy season, with $3.19 \pm 1.48 \mathrm{~h}$ vs. $2.28 \pm 0.403 \mathrm{~h}$ in the dry season, although the difference was not significant $(P=0.09$ ). (Table 1). It is noteworthy that in all cases pigs were drawn to both bovine and human fecal matter, sewage water and trash, during their displacement.

It should be noted that pigs move through areas that facilitate feeding, particularly sites where open defecation was detected, with average permanence times of $23 \pm 10.9$ and $35 \pm 15.2$ minutes in the dry and rainy seasons, respectively, and where they can rest. Figure 1 shows the displacement routes and the areas where pigs in Group 1 may consume human feces.

The animals covered a mean daily distance of $1266 \mathrm{~m}$ in $6.59 \mathrm{~h}$ in the dry season, and of $2416.66 \mathrm{~m}$ in $7.45 \mathrm{~h}$ in the rainy season $(P<0.05)$. The groups moved 250-300 $\mathrm{m}$ away from the household, and no contact was observed among the three groups under study (Figure 2).

By considering displacement radius of 200-300 $\mathrm{m}$ for all groups in the village, centered in the households where they are reared, the occurrence of a direct or indirect contact among all pigs in the location can be assumed (Figure 3).

\section{Discussion}

This study shows that when pigs are allowed to roam for food, they preferentially seek for landfills, sewages, and open defecation sites.

Pig breeding in semi-confinement has deep cultural and economic roots in the Americas since colonial times because it allows fattening animals with little budget by leaving them to roam freely, so they can procure their own maintenance (Del Rio, 1996). Unfortunately, this often results in the inclusion of human fecal matter in the diet of these animals, either because adequate sanitation services are not 


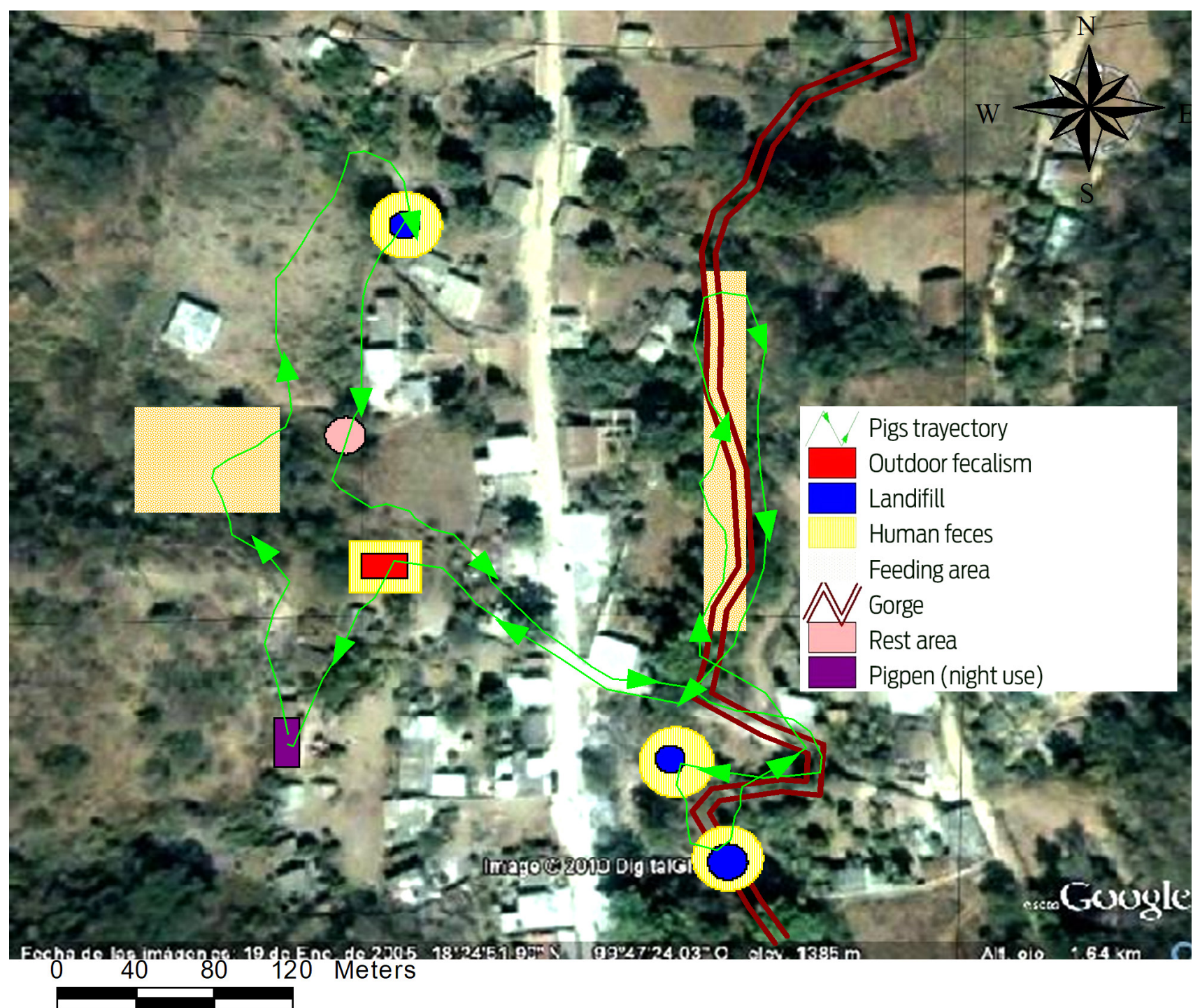

Figure 1. Trajectory of a group of pigs in places where they can rest and consume fecal matter. San Martín Pachivia, Guerrero, Mexico. 


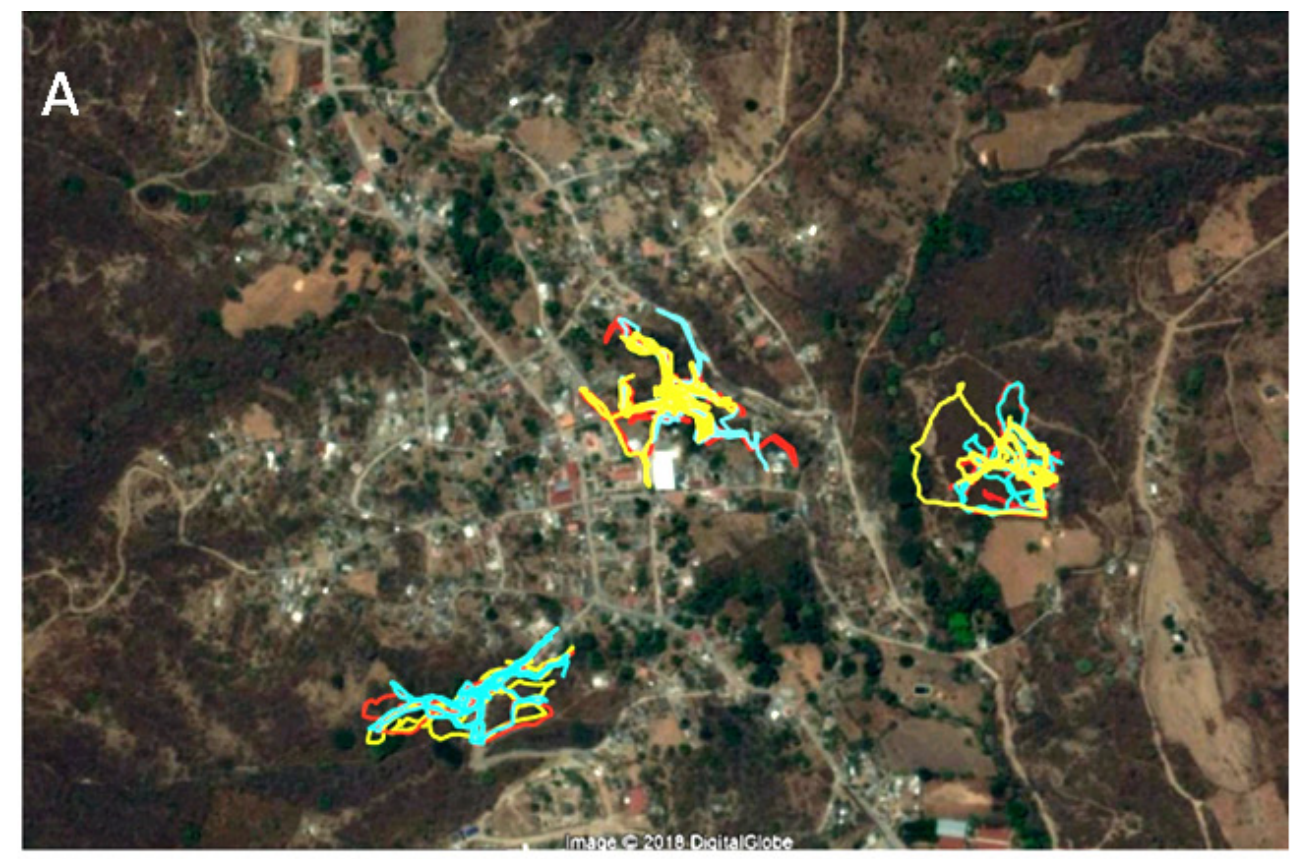

$\begin{array}{llllll}100 & 0 & 100 & 200 & 300 & 400 \mathrm{~m}\end{array}$

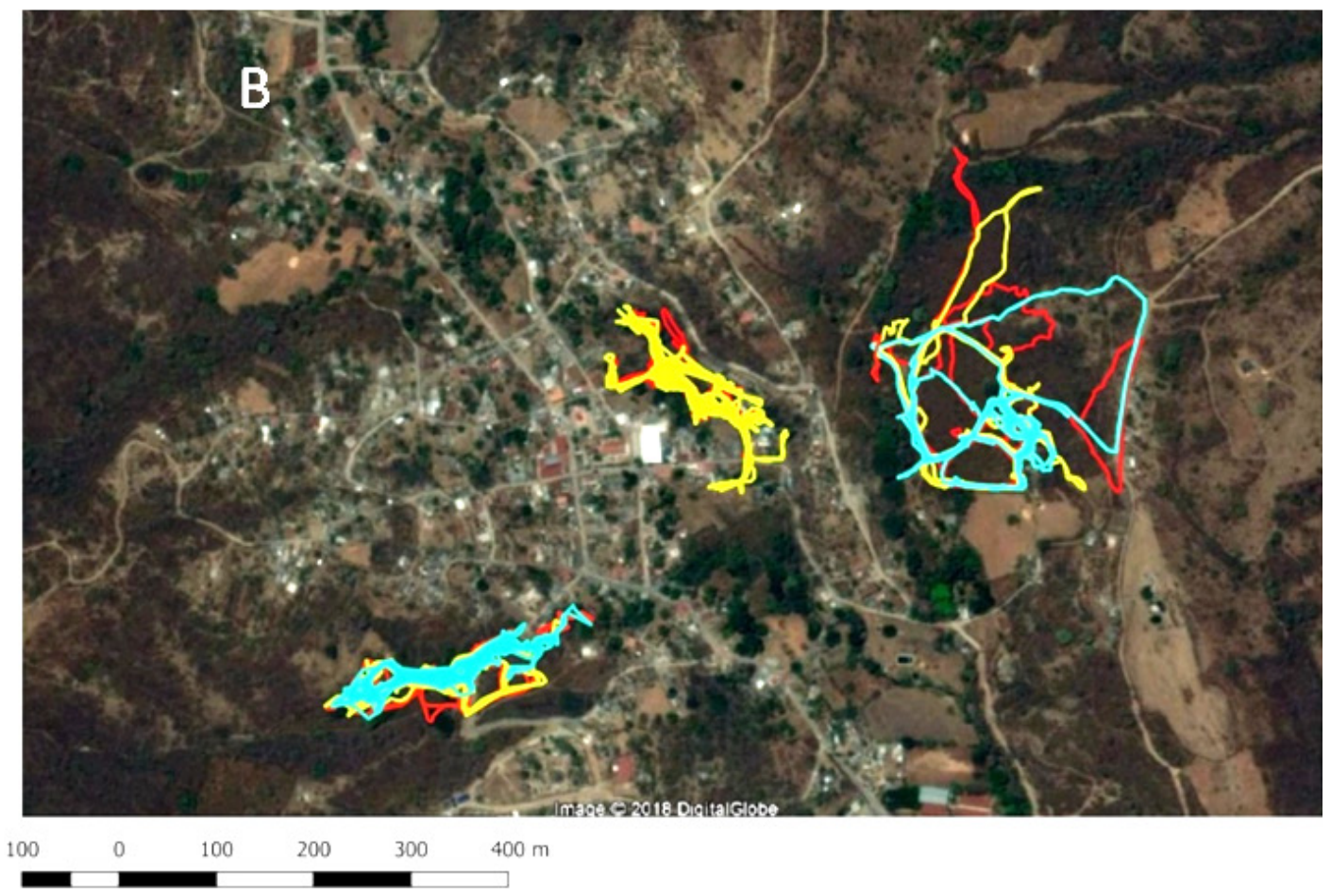

Figure 2. Trajectories of the three pig groups in two seasons of the year. San Martín Pachivia, Guerrero, Mexico. A Dry season. B Rainy season Each color represents pig displacement in a different day. 


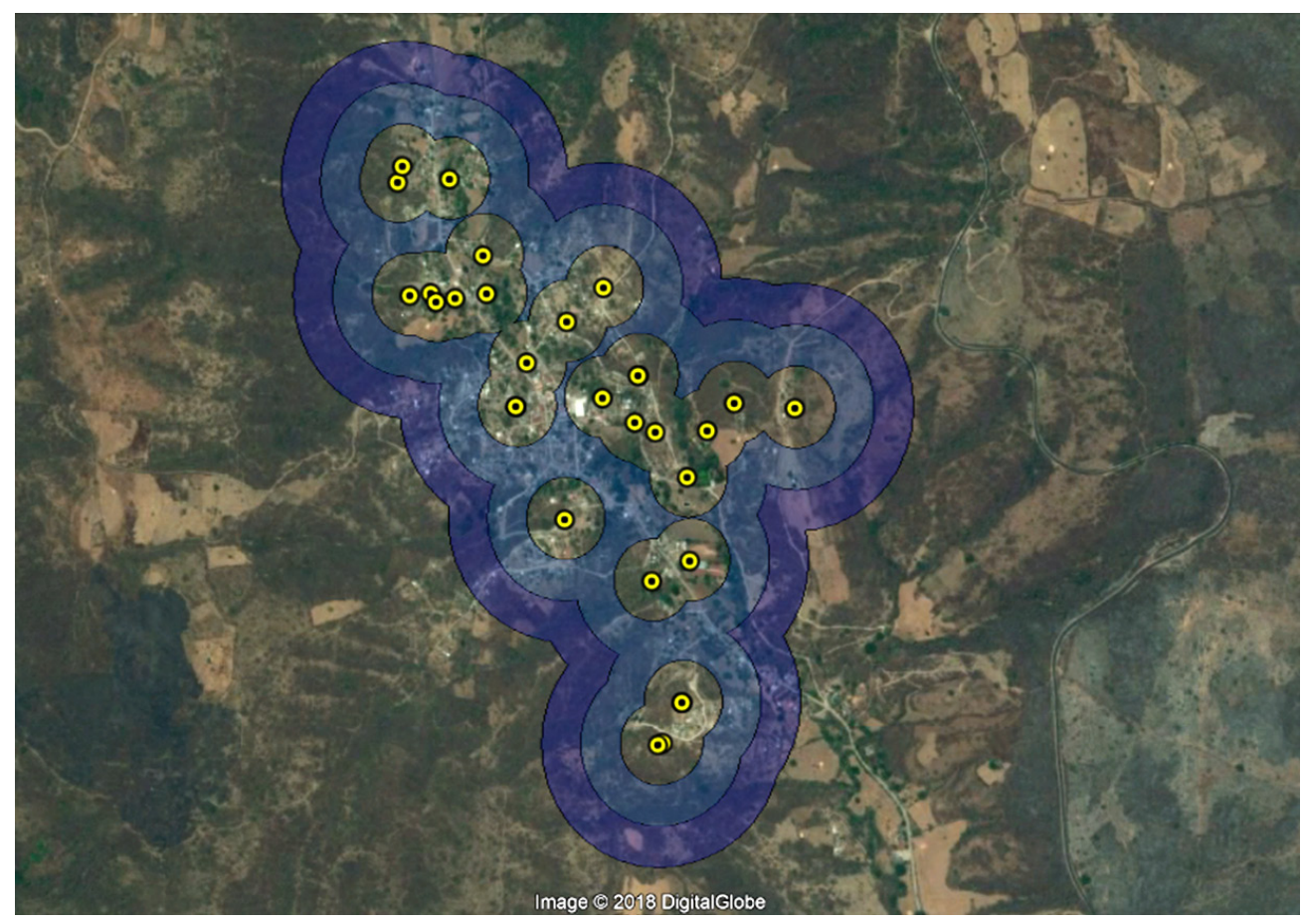

Figure 3. Pig movement radiuses in a Mexican location. Each circle represents a 100-m radius with respect to the site of households where pigs are reared. Located by GPS.

available or because open air defecation occurs during agricultural production activities. In any case, this favors the life cycle of parasites like T. solium.

With respect to the trajectories determined for the pig groups under study, the mean displacement of $1266 \mathrm{~m}$ in the dry and $2416 \mathrm{~m}$ in the rainy season of the year can influence the higher frequency of anti-Cysticercus antibodies found in the rainy season in all three groups. The longer trajectories recorded in the rainy season may increase the risk of exposure to contaminated sites and thus the acquisition of the parasite. On the other hand, the lack of differences in the distances covered by the pig groups could be due to the homogeneous conditions observed within the community.

As a first finding of this work, large aggregates of human feces were detected in the location, in some sort of outdoor toilets used by a large segment of San Martín Pachivia population. The sites containing feces are usually vacant plots or abandoned construction sites, most common in the outskirts of the village. Other routes often used by the pigs are ravines where makeshift sewers from several houses and latrines discharge. Pigs cover the same trajectories every day, and most of their exploration activity can be described as short movements within feces-rich patches combined with long linear displacements. A description of these movements could be used to suggest sites whose access should be restricted from pigs, and to stress the importance of changing hygiene practices and/or improving sanitary infrastructure.

Such measurements could include either restricting pig displacement (which would make extremely difficult to maintain this rearing system) or limiting the access of animals to areas of sanitary risk, like garbage dumps or wastewater disposal areas. As the recorded trajectories indicate, pigs visit extensively different parts of the locations that present homogeneously distributed exposure factors. This pattern explains the absence of differences in antibody seroprevalence between all three groups in each season. 
It should be noted that using a GPS to determine pig movement radiuses could allow us to infer the existence of contact with other pigs, which may be relevant to study pig-pig disease transmission, especially for those diseases transmitted by direct contact, such as viral infections like influenza, classical swine fever, or PRRS. It could also be a valuable tool to identify diseases that the pig does not acquire from other pigs but by ingesting contaminated human feces, like cysticercosis, echinococcosis, and amebiasis; this would help us to identify highly contaminated areas where sanitization measures should be applied, thus allowing us to devise more efficient preventive strategies.

It has been proposed that the variations in distance covered and displacement areas for most species are determined by intrinsic and extrinsic factors such as weather-related variables, terrain features like the presence of water bodies and crop fields, and individual specimen characteristics (Kay et al., 2017). Based on this, the variation in the distances covered by pigs in both seasons of the year can be explained considering that temperature at the study site varies markedly between both seasons. Thus, in the dry season (December to May) and particularly in April and May, temperatures up to $32{ }^{\circ} \mathrm{C}$ are often recorded at noon (https://es.climate-data.org/location/485718/); this temperature is out of the comfort range for pigs (Zimmerman et al., 2012), and the animals prefer to stay in the shade, resting and limiting displacement as much as possible.

The length of the trajectories registered are like those described for wild boars in the USA, where a maximum daily movement of 0.8-2.12 km was reported (Kay et al., 2017); however, the displacement values herein reported are lower than those described for domestic pigs in Kenya, where a movement up to $4 \mathrm{~km}$ per day was observed, in an approximate area of $10 \mathrm{~km}^{2}$ (Thomas et al., 2013). Pigs in San Martin Pachivia travelled a maximum of $300 \mathrm{~m}$ from the site they inhabit, a distance longer to that described in Peru, where a movement radius of $100 \mathrm{~m}$ was reported (Pray et al., 2016). The form of semi-confined rearing observed in the location under study is common in many regions of Mexico and even in other parts of the world where cysticercosis is endemic (Linares-Ibáñez et al., 2011; Copado et al., 2004; Pray et al., 2016; Pray et al., 2017). Thus, our results are relevant to other regions.

In this study, pig rearing was found in 33 households (13.04\%) of the location, yielding a human-pig ratio close to $5: 1$. This ratio is higher to that reported in other studies conducted in Mexico and Peru (Linares-Ibáñez et al., 2011 ; Pray et al., 2017).

A wide and even distribution of pigs was found in San Martín Pachivia, similar to that observed in other Mexican locations. However, it is different from the report by Martínez-Castañeda et al. (2012), where pigs were reared only in the periphery or in specific areas of the villages; this trait favors a direct or indirect interaction among all pigs and with the inhabitants of the location, at least in San Martín Pachivia.

With respect to the structure of pig groups, these are formed by males and females, young animals, adults, and piglets, with linear hierarchies. This structure was also observed in the three groups herein studied, which are formed by up to 15 animals. Each group was dominated by a sow, generally the oldest one, which owners usually keep as bloodstock.

This study explores a strategy to relate the trajectories of animal groups in a given space and time where the presence of some infectious disease has been hinted, to locate points with higher transmission of cysticercosis for the animals. 


\section{Acknowledgments}

The authors thank the Authorities and the inhabitants of San Martín Pachivia, Guerrero. Thank you to Juan Francisco Rodríguez for the copy of this manuscript. This work was supported financially by PAPIIT IN22661 and CONACYT (1 18047).

\section{Conflict of interest}

The authors have declared no conflict of interest.

\section{Author contributions}

MPM: He got the information, created the database, made the selection and monitoring of pigs in the community and recorded the trajectory of the pigs.

VN: She did the evaluation of cysticercosis in standing pigs, designed and applied the questionnaires, and participated in the writing of the document and its analysis.

MSJ: he made the selection and logistics in the community and obtained the samples

RM: He did spatial analysis of information related to trajectory evaluation.

SE: she performed the serological evaluation of pigs for the detection of porcine cysticercosis.

JMM: did the study design, statistical and epidemiological analysis, in addition he participated in the writing and analysis of the document.

\section{References}

Aluja de, A.S. and Villalobos, N. (2000). Cisticercosis por Taenia solium en cerdos de México. Veterinaria México, 31(3), p. 239-244.

Copado, F., Mayagoitia, L., Aluja de, S.A. and Galindo, F. (2004). The behaviour of free ranging pigs in the Mexican tropics and its relationships with human faeces consumption. Appl Anim Behav Sci, 88, p. 243-252.

Del Rio, M.J. (1996). El cerdo. Historia de un elemento esencial de la cultura castellana en la conquista y colonización de América (Siglo XVI). Anuario de Estudios Americanos, 53(1), p. 13-35.

FIRA. (2017). Programa Agroalimentario Carne de cerdo. Dirección de investigación y evaluación económica y sectorial.

Guy, Y.Z.S., Thomson, P.C. and Hermesch, S. (2012). Selection of pigs for improved coping with health and environmental challenges: breeding for resistance or tolerance? Front Gen, 3, p. 281.

Kay, S.L., Fischer, J.W., Monaghan, A.J., Beasley, J.C., Boughton, R., Campbell TA, et al. (2017). Quantifying drivers of wild pig movement across multiple spatial and temporal scales. Movement Ecology, 5, p. 14.

Linares-Ibáñez, J.A., Sciutto-Conde, E., Trujillo, O.M.E., Pérez-Rivero, J.J. and Martínez-Maya, J.J. (2011). Estructura etaria, comportamiento productivo y reproductivo de una población de cerdos criados en semiconfinamiento, en una comunidad rural del estado de Morelos, México. Veterinaria México, 42(4), p. 259-267.

Marotta, E., Lagreca, L. and Muñoz Luna, A. (1999). Conducta social, alimenticia y social del cerdo. Porci, Aula Veterinaria, Tratado de Ganado Porcino. Comportamiento y Bienestar Porcino (II). Madrid: Luzans.

Martínez Castañeda, F.E., Herrera Haro, J.G., García Contreras A.C. and Pérez Pérez, J. (2003). Indicadores productivos y de sustentabilidad económica de granjas 
porcinas urbanas en el norte de México D.F. (resultados preliminares). Arch. Zootec, 52, p. 101-104.

Martínez, M.J.J., Aluja, A.S., Martínez, V.N., Jaramillo, A.C.J. and Gemmell, M. (1997). Epidemiología de la cisticercosis en cerdos en una comunidad rural del estado de Guerrero, México. Veterinaria México, 28, p. 281-286.

Martínez-Castañeda, F. and Perea-Peña, M. (2012). Estrategias locales y de gestión para la porcicultura doméstica en localidades periurbanas del valle de México. Agricultura, Sociedad y Desarrollo, 9, p. 411-425.

Morales, J., Martínez, J.J., Villalobos, N., Hernández, M., Ramírez, R., Salgado-Estrada, B., et al. (2018). Persistent Taenia solium cysticercosis in the state of Morelos, Mexico: Human and Porcine Seroprevalence. J Parasitol, 104(5), p. 465-472.

Palma, A., Ortiz, B., Mendoza, L., Matamoros, G., Gabrie, J.A., Sánchez, A.L., et al. (2017). Molecular analysis of human- and pig-derived Ascaris in Honduras. J Helminthol, 17, p. 26:32.

Pray, W.I., Ayvar, V., Gamboa, R., Muro, C., Moyano, L.M., Benavides, V., et al. (2017). Spatial relationship between Taenia solium tapeworm carriers and necropsy cyst burden in pigs. PLoS Negl Trop Dis, 11 (4), p. e0005536.

Pray, W.I., Swanson, J.D., Ayvar, V., Muro, C., Moyano, L.M., Gonzalez, A.E., et al. (2016). GPS Tracking of Free-Ranging Pigs to Evaluate Ring Strategies for the Control of Cysticercosis/Taeniasis in Peru. PLoS Negl Trop Dis, 10(4), p. e0004591.

Thomas, L.F., de Glanville, W.A., Cook, A.E., Fèvre, E.M. (2013). The spatial ecology of free-ranging domestic pigs (Sus scrofa) in western Kenya. BMC Vet Res, 9, p. 46

Turchin, P. (1998). Quantitative analysis of movement: Measuring and modeling population redistribution in animals and plants. Storrs, CT: University of Connecticut.

Vitali, M., Dimauro, C., Sirri, R., Zappaterra, M., Zambonelli, P., Manca, E., et al. (2018). Effect of dietary polyunsaturated fatty acid and antioxidant supplementation on the transcriptional level of genes involved in lipid and energy metabolism in swine. PLOS ONE, 13(10), p. e0204869.

Wayne, W.D. (2002). Bioestadística. Base para el análisis de las ciencias de la salud. 4th edn. Mexico City: Limusa.

Weather Spark. (2021). Tiempo promedio en diciembre en San Martín Pachivia (Pachivia), México. Available at: https://es.weatherspark.com/m/5447/12/ Tiempo-promedio-en-diciembre-en-San-Mart\%C3\%ADn-Pachivia-(Pachivia)-M\%C3\%A9xico\#Sections-Temperature.

Zimmerman, J., Karriker, L., Ramirez, A., Schwartz, J.K., Stevenson, W.G. (2012). Diseases of swine. 10th edn. Hoboken, NJ: Wiley-Blackwell, p. 63. 